\title{
Foreground selection through SSRs markers for the development of salt tolerant rice variety
}

\author{
U. Mondal*, M. S. R. Khanom, L. Hassan and S. N. Begum ${ }^{1}$ \\ Department of Genetics and Plant Breeding, Bangladesh Agricultural University, Mymensingh-2202, Bangladesh and \\ ${ }^{1}$ Plant Breeding Division, Bangladesh Institute of Nuclear Agriculture, Mymensingh-2202, Bangladesh, *E-mail: \\ upamamondal@gmail.com
}

\begin{abstract}
Salinity is a great problem for rice production worldwide incurring substantial yield loss; a great threat towards food security. Marker-assisted backcrossing is one of the feasible methods to develop a new salt tolerant rice cultivar to cope with the challenge. The study was focused on to introgress salt tolerant genes from a tolerant rice line, FL-478 to Binadhan-7, an early, agronomically suitable and susceptible variety. Backcrossing was done during boro season; where Binadhan-7 was the recurrent parent and FL-478 was the donor parent. $141 \mathrm{BC}_{1} \mathrm{~F}_{1}$ lines were developed, which were subjected to foreground selection; the first level of selection of marker assisted backcrossing program. The aim of foreground selection was to identify the introgressed lines. $141 B_{1} C_{1} F_{1}$ populations were evaluated with tightly linked salt tolerant markers; AP3206f, RM3412b and RM336. A total of 47 heterozygous $B_{1} F_{1}$ lines were selected finally, which have alleles of both of the parents. Those introgressed lines could be efficiently used in further development of a stable early salt tolerant rice variety.
\end{abstract}

Keywords: Foreground selection, SSRs markers, Marker-assisted backcrossing

\section{Introduction}

Climate change and food security are the two burning issues now-a-days. Agricultural production is extremely vulnerable to climate change. It is causing threatening impacts on rice production, which is the most important cereal crop for the food security worldwide. Rice is the major source of food for more than 2.7 billion people on a daily basis in South and Southeast Asia (Hossain, 2005). In Bangladesh, rice grows in all the crop-growing seasons and occupies $77 \%$ of the total cropped area of 13.9 million hectares (BBS, 2010).

Salinity is one of the major natural hazards hampering rice production. Approximately $20 \%$ of irrigated areas worldwide (about 45 million ha) are estimated to suffer from salinity problems by various degrees (FAO, 2010). 21.5 million hectares of land areas in Asia are affected by salinity and estimated to cause up to $50 \%$ loss of fertile land by the mid of $21^{\text {st }}$ century (Linh et. al., 2012). In Bangladesh, The coastal saline soils are distributed unevenly in 64 upazillas of 13 Districts, covering portions of 8 AEZ of the country. These areas constitute about 2.5 million hectares which amount to about $18 \%$ of the total cropland of the country (Seraj and Salam, 2000). So in the concern of food security the necessity for enhancement in salt tolerance in rice is well understood.

Molecular marker technology offers a possibility by adopting a wide range of novel approaches to improve the selection strategies in rice breeding. Molecular markers that are linked to genes controlling salt tolerance could facilitate selection and improve rice varieties with salt tolerance having high heritability and expressivity. Microsatellite markers have been used effectively to map QTLs associated with salt tolerance (Singh et. al. 2007). Saltol, A major salinity tolerance QTL on rice chromosome 1, was mapped at IRRI using a recombinant inbred line (RIL) population between tolerant Pokkali and sensitive IR29; explaining $43 \%$ of the variation for seedling shoot Na+ uptake (Gregorio 1997, Elahi et. al. 2004). This QTL confers salinity tolerance at the vegetative stage of rice.

The use of DNA markers in backcrossing greatly increases the efficiency of selection, which is known as Marker-assisted backcrossing. The basis of MABC strategy is to incorporate one or a few genes into an adapted or elite variety or to transfer a gene/QTL from a donor line to a recipient line by repeated backcrossing. This approach develops an ideal genotype within a very short time avoiding the complicated issues related to transgenic technology and conventional breeding approaches. MABC 
approach is very advantageous with the following steps, (1) recombination and identification of target locus, known as 'foreground selection'; (2) minimizing linkage drag as recombinant selection; (3) harvesting maximum recurrent parent genome as background selection (Collard et. al. 2008). Although, the extent of effectiveness of this program is delimited by some factors, molecular breeding technologies are upgrading day by day, which has already been proven as the most effective technology for the development of salt tolerant varieties.

Hence, the attempt of this study was to introgress Saltol QTL into a popular variety Binadhan-7 by MABC method and to identify the introgressed lines through foreground selection using SSRs markers at early generation.

\section{Materials and Methods}

\section{Plant materials}

FL-478 (IR 66946-3R-178-1-1) was used as one of the parent for transferring salt tolerant QTL as it contains Saltol QTL on chromosome 1. It is a recombinant inbred line derived from (Pokkali X IR 29). It has a high level of seedling stage salinity tolerance in rice. Binadhan-7 is an early, high yielding transplanted aman variety was used as another parent. It is susceptible to salinity. A backcrossed program was conducted where, Binaadhan-7 was used as recurrent parent and FL-478 was the nonrecurrent donor parent. From that crossing program $23 F_{1}$ seeds were produced. The $F_{1}$ seeds were backcrossed with Binadhan- 7 to make $\mathrm{BC}_{1} \mathrm{~F}_{1}$ seeds.

\section{Cultural management}

For the ease of handling, the experiment was conducted on the plastic pot (bucket $10 \mathrm{~L}$ ). Recommended cultural operations were followed as and when necessary to ensure the normal plant growth and development.

\section{Development of backcross seeds}

Crossing scheme: Synchronization of flowering time is the most important operation for MABC program. To produce $B C_{1} F_{1}$ seeds, $F_{1}$ seeds were seeded in two sets at 14 days interval and recurrent parents were staggered in four sets starting from 15 January, 2012. First set of recurrent parent was seeded 7 days before the seeding $F_{1}$ generation. Second and third set were seeded in same time of $F_{1}$ generation and finally fourth set was seeded in 7 days after the seeding of $F_{1}$ generation.

Raising of backcross plants: 201 mature backcrossed seeds were collected 21 days after dusting. Seeds were dried into a seed dryer at $65^{\circ} \mathrm{C}$ for seven days and then set for germination. Among the 201 seeds, 171 sprouted seeds were grown in the pot. The seeds were seeded in two sets in order to ease the work pressure. Among those, 141 seedlings were survived and leaves were collected for foreground selection (Fig 1).

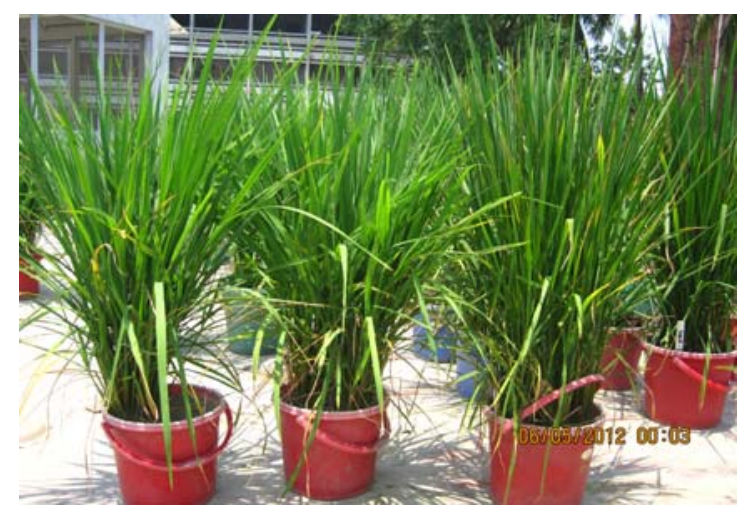

Fig 1. $\mathrm{BC}_{1} \mathrm{~F}_{1}$ generation in field 
Collection of leaf sample and DNA extraction: Samples were collected from young, vigorous leaves from 25 days old seedlings (Binadhan-7, FL-478, $\mathrm{BC}_{1} \mathrm{~F}_{1}$ population) to extract genomic DNA.NA. The collected leaf samples were placed in an ice box and finally the samples were stored in (-) $80^{\circ} \mathrm{C}$ freezer.

Using the Cetyl Trimethyl Ammonium Bromide (CTAB) mini-prep method, DNA was extracted from the leaves collected from at least 2-3 seedling of each genotype. The simplified mini scale procedure for DNA isolation in PCR analysis developed at IRRI was followed. The quality and quantity of the isolated DNA was sufficient for PCR analysis. Quantified DNA samples from each genotype were subjected to PCR amplification with SSR primers.

Polymorphism survey: Polymorphism survey of two parents and $\mathrm{BC}_{1} \mathrm{~F}_{1}$ populations were carried out using 7 foreground markers (RM585, RM336, RM3412b, RM10748, RM8094, AP3206 and AP3206f). Out of 7 markers, 3 markers (AP3206f, RM3412b and RM336) showed clear polymorphisms which were used in genotyping the foreground selection of the $141 \mathrm{BC}_{1} \mathrm{~F}_{1}$ rice lines for salt tolerant genotypes. The details of the primer are given in Table 1.

Table 1. The details of the microsatellite markers (SSRs) used for $B C_{1} F_{1}$ Survey

\begin{tabular}{|c|c|c|c|c|c|c|}
\hline $\begin{array}{l}\text { Primer } \\
\text { Name }\end{array}$ & $\begin{array}{l}\text { Chr.1 } \\
(\mathrm{Mb})\end{array}$ & $\begin{array}{l}\text { Nipponbare } \\
\text { size (bp) }\end{array}$ & Notes & & Sequence & $\begin{array}{c}\text { Annealing } \\
\text { temperature } \\
\left({ }^{\circ} \mathrm{C}\right)\end{array}$ \\
\hline \multirow{2}{*}{ AP3206f } & \multirow{2}{*}{11.2} & \multirow{2}{*}{167} & \multirow{2}{*}{$\begin{array}{c}\text { Foreground } \\
\text { marker }\end{array}$} & Forward & GCAAGAATTAATCCATGTGAAAGA & \multirow{2}{*}{55} \\
\hline & & & & Reverse & ATGCTCTGGCTCCCTCAAG & \\
\hline \multirow{2}{*}{ RM336 } & \multirow{2}{*}{11.6} & \multirow{2}{*}{175} & \multirow{2}{*}{$\begin{array}{c}\text { Foreground } \\
\text { marker }\end{array}$} & Forward & CTTACAGAGAAACGGCATCG & \multirow{2}{*}{55} \\
\hline & & & & Reverse & GCTGGTTTGTTTCAGGTTCG & \\
\hline \multirow{2}{*}{ RM3412b } & \multirow{2}{*}{11.5} & \multirow{2}{*}{110} & \multirow{2}{*}{$\begin{array}{c}\text { Foreground } \\
\text { marker }\end{array}$} & Forward & TCATGATGGATCTCTGAGGTG & \multirow{2}{*}{55} \\
\hline & & & & Reverse & GGGAGGATGCACTAATCTTTC & \\
\hline
\end{tabular}

PCR array: The PCR cocktail had total volume of $12.75 \mu \mathrm{L} /$ reaction containing $1.5 \mu \mathrm{L} 10 \mathrm{X}$ TB buffer (containing $200 \mathrm{mM}$ Tris- $\mathrm{HCl} \mathrm{pH} 8.3,500 \mathrm{mM} \mathrm{KCl}, 15 \mathrm{mM} \mathrm{MgCl}_{2}$ ), $0.75 \mu \mathrm{L}$ of $1 \mathrm{mM}$ dNTP, $1.0 \mu \mathrm{L}$ each of $5 \mu \mathrm{M}$ forward and reverse primers, and $0.25 \mu \mathrm{L}$ of Taq DNA polymerase with required $\mathrm{ddH}_{2} \mathrm{O} .2 \mu \mathrm{L}$ genomic DNA (5-25 ng of DNA Template) was added PCR cocktail. The steps of PCR reactions were: initial denaturation for 5 minutes at $94^{\circ} \mathrm{C}$, then annealing at $55^{\circ} \mathrm{C}$ for 1 minute. Polymerization for 2 minutes at $72^{\circ} \mathrm{C}$ to complete a cycle and cycle was repeated for 34 times. The final extension duration was 7 minutes at $72^{\circ} \mathrm{C}$. then, PCR products were mixed with $3 \mu \mathrm{l}$ of $2 \mathrm{X}$ gel loading dye. Polymorphisms in the PCR products were analyzed by electrophoresis using mini vertical polyacrylamide gels for high throughput manual genotyping. The gels were stained in ethidium bromide and documented using BIOMETRA Gel Documentation System.

\section{Data analysis}

Scoring of bands: The pattern of bands obtained after amplification with the primers was scored with reference to two parents. The band having same level of FL-478 was scored as ' $T$ ' which indicated the homozygous allele of the tolerant parent for a particular microsatellite marker. Similarly, the bands with similar level of Binadhan-7 was scored as ' $\mathrm{S}$ '. The heterozygous alleles having both the bands of two parents were scored as ' $\mathrm{H}$ '.

Allele scoring: With the help of Alpha Ease FC 5.0 software, the size (in nucleotide base pairs) of the amplified band for each SSR marker was determined based on its migration relative to 20bp DNA Ladder (a molecular weight size marker).

Analysis of SSR Data: The summary statistics including the number of alleles per locus, major allele frequency, gene diversity and Polymorphism Information Content (PIC) values were determined using POWER MARKER version 3.23 (Liu and Muse 2005), a genetic analysis software. Polymorphism Information Content (PIC) value described and modified by Anderson E. (1993) for self-pollinated species. 
Estimation of gene and genotypic frequencies: The proportions of different alleles of a gene present in a Mendelian population are known as gene frequency. Gene frequencies in a population can be readily estimated by the total number of each of the alleles of the gene present in these individuals and their ratio to the total number for all the alleles of the gene is estimated. The proportions of different genotypes for a gene in a population are known as genotypic frequencies for that gene; often they are also called zygotic frequencies.

\section{Results and Discussion}

\section{Parental polymorphism}

Primer survey is very essential before starting marker-assisted backcross breeding Monomorphic markers can not distinguish the two parental genotypes, so this type of marker bears no value in selection work. For selection of the Saltol locus (foreground selection), seven tightly linked SSR markers to the Saltol positioning at 11.2 to $11.7 \mathrm{Mb}$ were used. Out of seven SSR primers, three RM336, RM3412b, and AP3206f showed polymorphisms for the parents.

\section{Allelic information}

Using the SSR markers, alleles were detected among the $141 \mathrm{BC}_{1} \mathrm{~F}_{1}$ populations along with their parents. According to Nei's (1983), the highest level of gene diversity value (0.69) was observed in loci RM3412b and the lowest level of gene diversity value (0.438) was observed in loci AP3206f with a mean diversity of 0.5260 (Table 2). The maximum number of repeats within the SSRs was also positively correlated with the genetic diversity. The PIC value was calculated to estimate the informativeness of each primer. The PIC values ranged from a low of 0.3454 (AP3206f) to a high of 0.6445 (RM3412b) with an average of 0.4460 (Table 2). So, the primer RM $3412 \mathrm{~b}$ was found to be superior for analysis of genetic diversity among the markers in this region.

The result was consistent with the previous study of Mohammadi-nejad, et. al. (2010), where the PIC value varied from 0.56 to 0.88 which was also highly correlated the allele size range and the number of motif.

Table 2. Allelic informations found among $141 \mathrm{BC}_{1} \mathrm{~F}_{1}$ populations of Binadhan-7 $\mathrm{x}$ FL 478 along with their parents for 3 microsatellites (SSR) markers

\begin{tabular}{|c|c|c|c|c|c|c|}
\hline Locus & $\begin{array}{c}\text { Repeat } \\
\text { motif }\end{array}$ & $\begin{array}{c}\text { Amplicon } \\
\text { Size ranges }\end{array}$ & $\begin{array}{c}\text { Major allele } \\
\text { frequency }\end{array}$ & PIC & Sample size & Gene Diversity \\
\hline AP3206f & (GT)10 & $136-177$ & 0.43 & 0.3454 & 143 & 0.4386 \\
\hline RM3412b & (TA)34 & $98-117$ & 0.67 & 0.6445 & 143 & 0.6959 \\
\hline RM 336 & (CTT)18 & $144-195$ & 0.68 & 0.3482 & 143 & 0.4436 \\
\hline Total & - & - & - & 1.3381 & - & 1.5755 \\
\hline Mean & - & - & 0.59 & 0.4460 & 143 & 0.5260 \\
\hline
\end{tabular}

\section{Genotypic performance of backcross population $B_{1} F_{1}$ at foreground selection}

For foreground selection in the $\mathrm{BC}_{1} \mathrm{~F}_{1}$ generation, individual plants that were heterozygous at the Saltol locus were identified reducing the population size for further screening. For each of the marker, allelic bands were scored based on the parental bands and designated as ' $T$ ' for tolerant, ' $S$ ' for susceptible and ' $\mathrm{H}$ ' for heterozygous. $141 \mathrm{BC}_{1} \mathrm{~F}_{1}$ lines showed variation in foreground selection with 3 tightly linked salt tolerant primers (Fig 2-4). Out of $141 \mathrm{BC}_{1} \mathrm{~F}_{1}$ plants, the marker AP3206f identified 60 plants as heterozygous, RM3412b identified 59 plants and the RM336 identified 65 plants as heterozygous (Table 3).

$47 \mathrm{BC}_{1} \mathrm{~F}_{1}$ plants were selected based on the heterozygous nature of all the target loci at Saltol region. Those lines can be used for further selection step of marker aided backcrossing. Similar result was found in the study of Rahman (2011) to introgress Saltol QTL into BR28 from FL-478. He found 94 heterozygous plants out of $230 \mathrm{BC}_{1} \mathrm{~F}_{1}$ rice lines using foreground markers. 


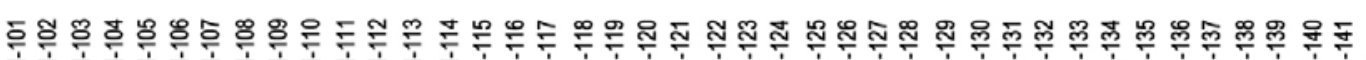

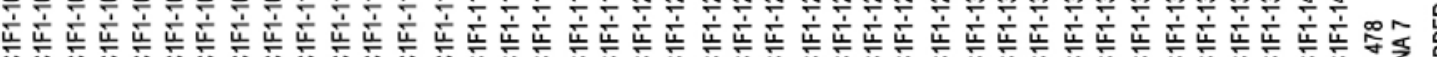

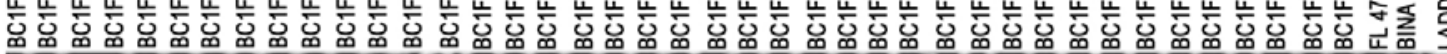

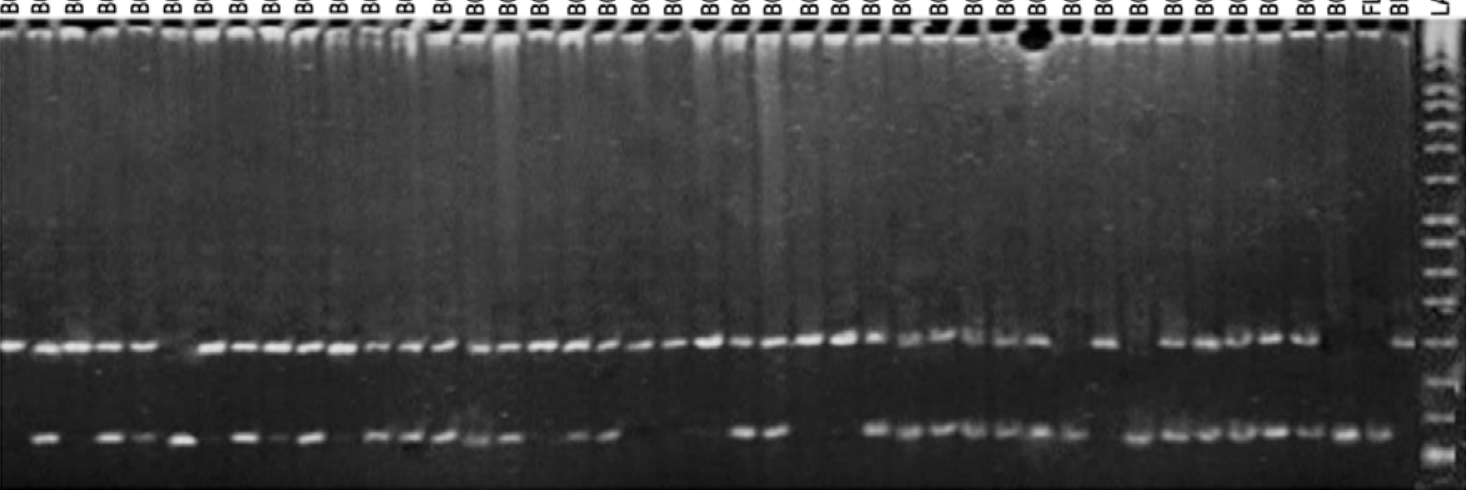

Fig. 2. Banding pattern of $B C_{1} F_{1}$ population of Binadhan-7/FL-478 using SSR marker AP3206f

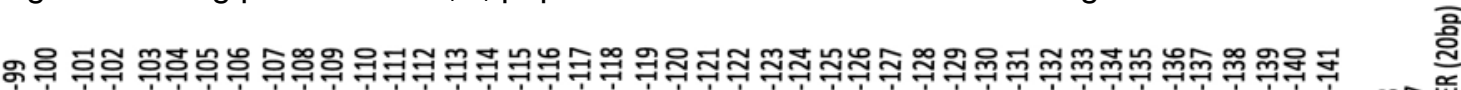

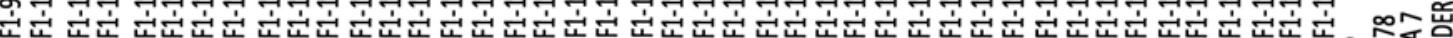

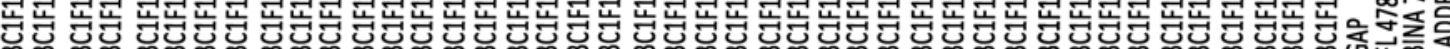

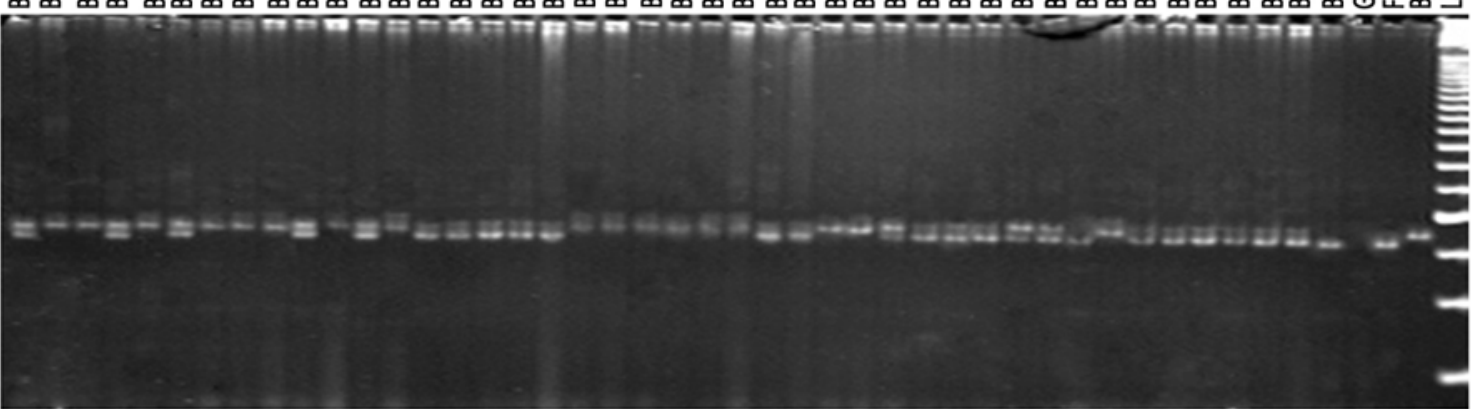

Fig. 3. Banding pattern of $\mathrm{BC}_{1} \mathrm{~F}_{1}$ population of Binadhan-7/FL-478 using SSR marker RM3412b

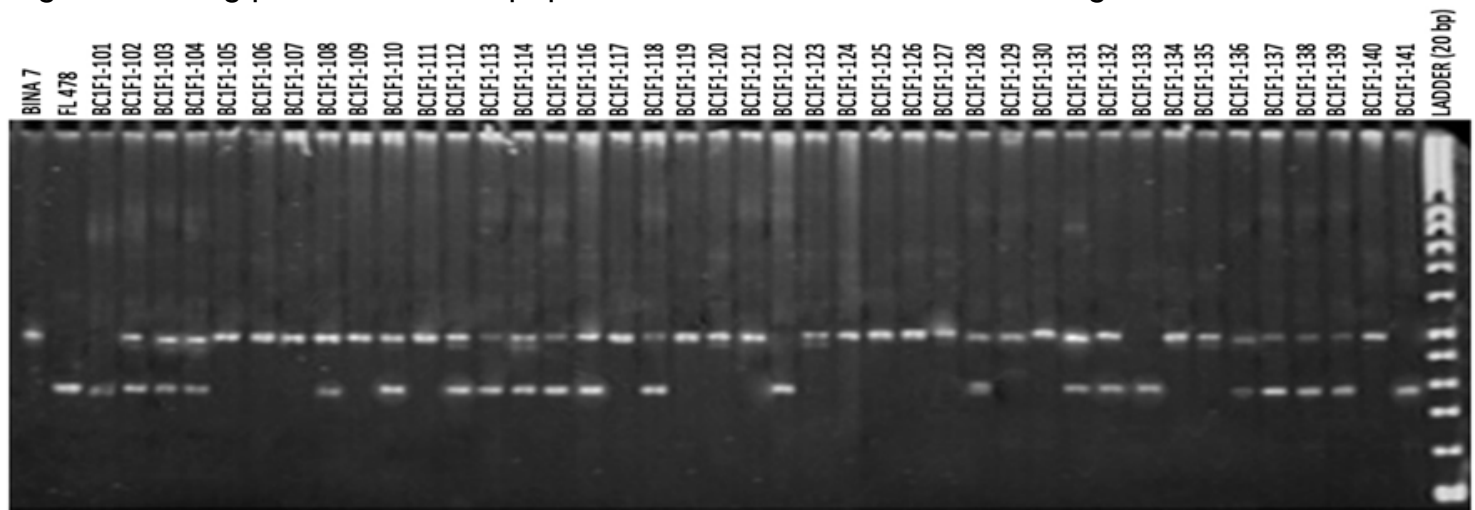

Fig. 4. Banding pattern of $\mathrm{BC}_{1} \mathrm{~F}_{1}$ population of Binadhan-7/FL-478 using SSR marker RM336

Table 3. $141 \mathrm{BC}_{1} \mathrm{~F}_{1}$ populations with respect to the alleles amplified by the microsatellite primer i.e., AP3206f, RM3412b and RM336

\begin{tabular}{|c|c|c|c|c|}
\hline \multirow{2}{*}{$\begin{array}{l}\text { Name of } \\
\text { Primers }\end{array}$} & \multirow{2}{*}{$\begin{array}{c}\text { Total number } \\
\text { of } \\
\mathrm{BC}_{1} \mathrm{~F}_{1} \text { lines }\end{array}$} & \multicolumn{3}{|c|}{ Patterns of $\mathrm{BC}_{1} \mathrm{~F}_{1}$ population } \\
\hline & & $\begin{array}{l}\text { Susceptible type } \\
\text { (Binadhan-7) }\end{array}$ & $\begin{array}{c}\text { Tolerant type } \\
\text { (FL478) }\end{array}$ & Heterozygous \\
\hline AP3206f & \multirow{3}{*}{141} & 65 & 15 & 60 \\
\hline RM3412b & & 68 & 13 & 59 \\
\hline RM336 & & 58 & 18 & 65 \\
\hline
\end{tabular}




\section{Gene and Genotypic Frequency}

The proportions of tolerant and susceptible alleles are 0.32 and 0.67 for marker AP3206f and 0.301, 0.69 for marker RM3412b. In case of RM336 the proportions are 0.358 and 0.641 . The proportions of susceptible, heterozygous and tolerant genotypes are $0.46,0.40$ and 0.1 for marker AP3206f. For $\mathrm{RM} 3412 \mathrm{~b}$ the proportions are $0.44,0.45$ and 0.09 respectively. In case of RM336 the proportion is 0.41 , 0.46 and 0.127 . In this study, the average proportions of susceptible and heterozygous genotypes were 0.44 and 0.43 respectively; which indicated that the results fitted to the expected 1:1 ratio of this generation (chi squre value $=0.48$ at a significant level of 0.05 ).

Similar result was found in the study of Iftekharudaula (2008), who also found 1:1 ratio at $B_{1} F_{1}$ generation with a non-significant chi square value of 0.28 at a probability level of 0.05 .

\section{Conclusion}

Salinity stress is the most serious factors that limit the rice (Oryza sativa L.) production worldwide and brought an enormous challenge for food security in developing countries. Breeding of rice varieties with in-built salt tolerance is realized as the most promising, less resource consuming, economically viable and socially acceptable approach. Marker aided backcrossing can be used as an efficient tool for this. After conducting foreground selection, $47 \mathrm{BC}_{1} \mathrm{~F}_{1}$ lines were selected for further recombinant and background selection to minimize 'linkage drag' while recovering more genetic background of recurrent parent. Three foreground markers AP3206f, RM3412b and RM336 showed polymorphism among the rice lines, could facilitate selection, mapping, cloning genes, QTL analysis and so on, which in turn increase rice production in saline environments.

\section{Acknowledgements}

The authors would like to thank the staff and lab mates at Bangladesh Institute of Nuclear Agriculture for all technical assistance. Thanks also go to all the teachers of the department of Genetics and Plant Breeding, Bangladesh Agricultural University,Mymensingh, for their valuable advice and suggestions.

\section{References}

Anderson, E. 1993. A semi graphical method for the analysis of complex problems. Proceeding of National Academy of Science, USA, 48: 923-927.

BBS, 2010. Agriculture Wing. Bangladesh Bureau of statistics, Ministry of planning, Government of the People's Republic of Bangladesh, Dhaka. 54.

Collard B.C.Y and Mackill, D.J. 2008. "Marker-Assisted Selection: An Approach for Precision Plant Breeding in the 21st Century," Philosophical Transactions of the Royal Society, Vol. 363, No. 1491, pp. 557-572.

Elahi, C.M.F., Seraj, Z.I., Rasul, N.M., Das, K.C., Biswas, K., Salam, M.A., Gomosta, A.R., Tumimbang, E., Adorada, D., Gregorio, G. and Bennett, J. 2004. Breeding rice for salinity tolerance using the Pokkali allele: finding a linked DNA marker. In: In Vitro Culture, Transformation and Molecular markers for Crop Improvement. Ed. Islam A.S. Science Publishers, Inc, USA. pp. 157-170.

Food and Agriculture Organization. 2010. "Report of salt affected agriculture," http://www.fao.org

Gregorio, G.B. 1997. Tagging salinity tolerance genes in rice using amplified fragment length polymorphism (AFLP). PhD. thesis, University of the Philippines, Los Baños.; $118 \mathrm{p}$

Hossain, M. 2005. Rice production and market: trends and outlook. Paper presented at the IFA Regional Conference for Asia and Pacific, December 6-8, Singapore.

Iftekharudaula, K.M. 2008. Comparison of New Selection Strategies or Marker Assisted Backcrossing for a Submergence Tolerant Gene in Rice. Ph. D. dissertation. Bangladesh agricultural University, Mymensingh, Bangladesh, pp. 1-205.

Linh, H.L., Linh, T.H., Xuan, T.D., Ham, L.H., Ismail, M.A., Khanh, T.D. 2012. Molecular Breeding to Improve Salt Tolerance of Rice (Oryza sativa L.) in the Red River Delta of Vietnam. International Journal of Plant Genomics. 10: 1-9.

Liu, K. and Muse, S.V. 2005. Power Marker: Integrated analysis environment for genetic marker data. Bioinformatics, 21: $2128-2129$

Mohammadi-Nejad, G., Singh, R.K., Arzani, A., Rezaie, A.M., Sabouri, H. and Gregorio, G.B. 2010. Evaluation of salinity tolerance in rice genotypes. International Journal of Plant Production, 4: 199-208.

Nei M. 1983. Analysis of gene diversity in subdivided populations. Proceeding of National Academy of Science, USA, 70: 33213323.

Rahman, M.A. 2011. Marker-assisted backcrossing of saltol, discovery of additional quantitative trait loci and assessment of allelic variability in saltol in rice germplasm. Ph. D. dissertation. Bangladesh Agricultural University, Mymensingh, Bangladesh, pp. 1-268.

Seraj, Z.I. and Salam, M.A. 2000. Growing rice in saline soils. The Biotechnology Directory. Macmillan Reference Ltd., Porters South, Crinan Street, London.

Singh, R.K., Gregorio, G.B. and Jain, R.K. 2007. QTL mapping for salinity tolerance in rice. Physiology and Molecular Biology of Plants, 13: 87-99. 